\title{
NOTE ON THE REACTION OF ACETIN WITH ALCOHOLIC POTASH.
}

Bx A. H. Allen and D. Homfrex.

Srnce the paper on "The Composition of Butter-fat" was read by one of us at the June meeting of the Society of Public Analysts, we have made some experiments with a view of ascertaining whether glyceryl acetate (acetin) behaved with alcoholic potash in a manner similar to glyceryl butyrate (butyrin); in other words, whether on heating acetin with a quantity of alcoholic potash insufficient for its complete saponification a notable amount of ethyl acetate (acetic ether) could be produced.

Some acetin was prepared by heating together 5 parts of glycerin with 6 of anhydrous sodium acetate and 15 of acetic anhydride. The mixture was kept boiling for an hour in a flask furnished with a reflux condenser. It was then treated with water, and sodium carbonate added till the reaction was permanently alkaline, when the liquid was shaken with ether, which was separated, and the acetin recovered by distilling off the solvent. 
One gramme of the acetin thus prepared was distilled with 30 c.c. of alcohol and 0.5 c.e. of alcoholic potash containing 80 grammes of caustic potash per litre. The distillate, which smelt strongly of acetic ether, was heated on the water-bath for halfan-hour with 10 c.c. of the same alcoholic potash solution ( $=11.8$ c.c. normal $\mathrm{KHO}$ ), and the excess of alkali titrated back with standard hydrochloric acid and phenolphthalein in the usual way. From this result we calculated the weight of acetic acid volatilised as acetic ether. The residue in the retort was treated with more alcohol and another 0.5 c.c. of alcoholic potash, the liquid distilled, and the distillate saponified as before. The following results were obtained, operating on one gramme of acetin in each case :-

\begin{tabular}{|c|c|c|c|c|c|c|c|}
\hline \multirow{2}{*}{\multicolumn{2}{|c|}{ A. 1st Distillate }} & \multicolumn{3}{|c|}{ employed. } & \multirow{3}{*}{$\begin{array}{c}\text { in distillate. } \\
53 \cdot 4 \% \\
17 \cdot 4 \%\end{array}$} & \multirow{3}{*}{$\begin{array}{l}= \\
\ldots \\
\ldots\end{array}$} & \multirow{3}{*}{$\begin{array}{l}\text { Acetin. } \\
65.12 \% \\
21.22 \%\end{array}$} \\
\hline & & 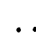 & 0.5 & . & & & \\
\hline & 2nd & . & $0 \cdot 5$ & . . & & & \\
\hline \multirow{4}{*}{ B. } & Total & . & 1.0 & $\ldots$ & $70 \cdot 8$, & $\ldots$ & $86 \cdot 34 .$, \\
\hline & 1st Distillate & $\cdots$ & 0.2 & . & $43.8 \%$ & .. & $53.41 \%$ \\
\hline & Do. & $\cdots$ & $1 \cdot 0$ & . & 26.4, & $\cdots$ & $32 \cdot 19$, \\
\hline & Total & . & $1 \cdot 2$ & $\ldots$ & $70 \cdot 2$, & $\ldots$ & $85-60$, \\
\hline
\end{tabular}

The theoretical yield of acetic acid, supposing the whole of the substance employed to be pure triacetin and the conversion into ethyl acetate to have been complete, would be 0.826 against 0.708 and 0.702 grammes actually produced.

A fresh quantity of acetin was next prepared, and an experiment made to ascertain if it volatilised with alcohol. 1.0848 gramme of acetin was distilled over with 50 c.c. of alcohol, the distillate and residue both saponified, and the acetin calculated as before. In the distillate only 0.015 of acetic acid was found, while the residue contained 0.752 gramme, the sum of the two being 0.767 gramme. This result shows that the extra. ordinary results previously obtained were not due to actual volatilisation of acetin as such. The total yield of acetic acid is below the theoretical amount (0.826 gramme) doubtless owing to the presence of mono- or di-acetin in the material employed. That it was not due to any error of experiment was proved by saponifying a known weight of the acetin with excess of alcoholic soda ( $\frac{N}{5}$ normal) under a reflex condenser, and ascertaining the alkali consumed in the reaction by titration with standard acid and phenolphthalein in the usual way. A yield cf 76.03 per cent. of acetic acid was obtained, as against $76 \cdot \overline{7}$ recorded above.

Another experiment was then made by distilling 1.135 gramme of the same specimen of acetin with 1.0 c.c. of $\underset{5}{\mathrm{~N}}$ normal soda and 30 c.c. of alcohol. The distillate was saponified with a known quantity of the same alcoholic soda and titrated back with hydrochloric acid as usual. The residue in the retort was again distilled with alcohol and 1.0 c.c. of the same soda solution, and this treatment was repeated once more. The following are the figures obtained :-

\begin{tabular}{|c|c|c|c|c|c|}
\hline \multirow[b]{2}{*}{ 1st Distillate } & \multicolumn{2}{|c|}{$\begin{array}{l}\text { Alcoholic NaHO } \\
\text { employed. }\end{array}$} & \multirow{4}{*}{$\begin{array}{c}\text { Acetic Acid } \\
\text { in distillate. } \\
32.19 \% \\
26.22 \% \\
11.00 \%\end{array}$} & \multirow{3}{*}{$\begin{array}{l}= \\
\therefore\end{array}$} & \multirow{2}{*}{$\begin{array}{c}\text { Acetin. } \\
3902 \%\end{array}$} \\
\hline & . $\quad 10$ & .. & & & \\
\hline Do. & $1 \cdot 0$ & .. & & & $31 \cdot 97$, \\
\hline Do. & 1.0 & . & & $\ldots$ & $13 \cdot 41$, \\
\hline Total & $3 \cdot 0$ & . & $69 \cdot 41$ & - & $84 \cdot 40$, \\
\hline
\end{tabular}


The volume of the caustic soda solution requisite to completely saponify the $1 \cdot 135$ gramme of acetin employed would be 50 c.c. Hence 1 c.c. of the alkaline solution is chemically sufficient to saponify only about one-fiftieth of the acetin used, and yet it causes the conversion of 39 per cent. of it into acetic ether, while 3 c.c. converts the large proportion of $84 \cdot 4$ per cent.

It seems desirable to place these remarkable results on record, but we refrain for the present from attempting any explanation of the curious reaction in question.

Two supplementary experiments deserve mention. 1 gramme of anhydrous sodium acetate was distilled with 50 c.c. of alcohol, the distillate boiled with alkali and titrated with standard acid, when it was found that no acetic ether had been formed. A mixture of acetin, alcohol, and anhydrous sodium acetate gave a small yield of acetic ether, the acetic acid corresponding to 5.26 per cent. of the acetin employed. 